\title{
Aspects of scientific explanation in Auguste Comte
}

\section{Vincent Guillin}

\section{(2) OpenEdition}

\section{Journals}

Electronic version

URL: http://journals.openedition.org/ress/3589

DOI: $10.4000 /$ ress.3589

ISBN: 1663-4446

ISSN: $1663-4446$

Publisher

Librairie Droz

Printed version

Date of publication: 30 November 2016

Number of pages: 17-41

ISSN: 0048-8046

\section{Electronic reference}

Vincent Guillin, "Aspects of scientific explanation in Auguste Comte », Revue européenne des sciences sociales [Online], 54-2 | 2016, Online since 30 November 2019, connection on 04 January 2020. URL : http://journals.openedition.org/ress/3589; DOI : 10.4000/ress.3589 


\title{
ASPECTS OF SCIENTIFIC EXPLANATION IN AUGUSTE COMTE
}

\author{
VINCENT GUILLIN \\ Université du Québec à Montréal, CIRST \\ guillin.vincent_philippe@uqam.ca
}

\begin{abstract}
According to the received view, the positivist conception of explanation primarily consists in the idea that a good explanation should aim at promoting the unification and understanding of phenomena through the discovery of their empirical laws. Although Auguste Comte undoubtedly subscribed to such a view, his positions on the matter were somewhat more complex. In my paper, I propose an outline of his ideas with respect to explanation that draws particular attention to the limits he set to it, to the causal considerations he made room for and to the ways his general explanatory framework applied to the study of social phenomena.
\end{abstract}

Keywords: causation, Auguste Comte, development, explanation, laws, positivism.

Résumé. On s'accorde généralement sur le fait que la conception positiviste de l'explication consiste avant tout dans l'idée qu'une bonne explication devrait viser à promouvoir l'unification et l'intelligibilité des phénomènes au moyen de la découverte de leurs lois empiriques. Même si Auguste Comte a bien souscrit à une telle vision, ses positions sur le sujet étaient néanmoins plus complexes que cela. Dans mon article, je propose une vue d'ensemble de ses idées sur l'explication qui porte une attention particulière aux limites qu'il lui donnait, aux considérations causales auxquelles il faisait une place et aux différentes façons dont son schéma explicatif général s'appliquait à l'étude des phénomènes sociaux.

Mots-clés: causalité, Auguste Comte, développement, explication, lois, positivisme. 


\section{INTRODUCTION}

Boasting aside, Auguste Comte was surely right in considering his discovery of the "law of the three states" a most outstanding philosophical achievement. For that generalization about the development of human intelligence, which claimed that "each branch of our knowledge [...] passes in succession through three different theoretical states", namely "the theological or fictitious state, the metaphysical or abstract, and the scientific or positive state" (Comte, 1975 [1830-I842], vol.I, l.I, p.2I)', was not only to be seen as a proper explanation of the mental evolution of mankind, thereby paving the way for the advent of a science of social phenomena. It also provided, through the comparison of these "three methods of philosophizing" (ibid.), the various criteria according to which the scientific value of that very explanation, and in fact of any explanation whatsoever, could be assessed. Accordingly, since the "law of the three states" was indeed, with respect both to its intent and content, all about explanation, one is undoubtedly warranted in choosing it as a convenient starting point for outlining Comte's views on the matter.

In what follows, I will therefore present an overview of Comte's general conception of scientific explanation that, in addition to summarizing the most well-known features of his views (namely, that a positive explanation must promote the unification and understanding of phenomena through the discovery of their empirical laws), will single out some lesser known elements: the astronomical model on which Comte drew to articulate his notion of explanation; his opposition to universal or reductionist explanations; his qualified acceptance of hypotheses as explanatory devices; the room he made for causal considerations in explanations and the methods he advocated to assess them. I then turn more specifically to the topic of sociological explanations and to the various forms they might take, before focusing on the way Comte dealt with non-social causes such as race and climate in his accounts of social phenomena. Finally, I will consider one last aspect of explanation, that of explanation as development, which suffuses Comte's conception of social evolution.

I In this paper, all references to the Cours de philosophie positive will be quoted from Comte, 1975 (1830-1842), with the indication of volume, lesson and page; references to the Système de politique politique positive will be drawn from Comte, 1929 (1850-1854), with the indication of volume, chapter, and page. All translations are mine. 


\section{I.MODES OF EXPLANATIONS}

As Laurent Fedi rightly points out, the law of the three states primarily consisted in a description of the "modes of explanation the human mind has used in its progressive and continuous effort to account for the 'phenomena' or the "facts"' (Fedi, 2000, p.49). In the classic presentation offered in the First Lesson of the Cours de philosophie positive, such a description proceeded by way of a contrast being drawn between the explanatory schemes distinctive of each of the three states of human mental development. In the theological state, "the human mind directs its researches mainly towards the inner nature of beings, and towards the first and final causes of all the phenomena it observes" and "represents these phenomena as being produced by the direct and continuous action of more or less numerous supernatural agents, whose arbitrary intervention explains all the apparent anomalies of the universe" (Comte, 1975 [1830-1842], vol.ı, l.ı, p.2ı, italics mine). "In the metaphysical state, Comte went on, the supernatural agents are replaced by abstract forces, real entities or personified abstractions, inherent in the different beings of the world", these entities being held "capable of giving rise by themselves to all the phenomena observed, each phenomena being explained by assigning to its corresponding entity" (ibid., italics mine). Eventually, "in the positive state, the human mind [...] endeavors to discover, by a well-combined use of reasoning and observation, the actual laws of phenomena - that is to say, their invariable relations of succession and likeness" (ibid., p.2I-22). In that final state, "the explanation of facts [...] consists henceforth only in the connection established between different particular phenomena and some general facts" (ibid., p.22, italics mine).

Although the exact difference between the theological and metaphysical modes of explanation seems a bit elusive at first (apart from the consideration that metaphysical explanations seem to be less anthropomorphic-pointing towards "entities" rather than "agents"-and more generic - focusing on the causes of "all observed phenomena" instead of "the apparent anomalies of the universe" - than theological ones), the distinction between those and the positive or scientific mode is more straightforward: whereas the theological and metaphysical mindsets look for explanations that invoke causes that transcend 
sensory experience, act non-mechanically or teleologically, and operate on the inner, i.e. non-empirically observable, constitution of things, by contrast, from the positive standpoint, a particular fact or phenomenon is said to have been explained when there exists an empirically warranted proposition, stating a general observable connection, either temporal or of resemblance, between phenomena or facts, under which it can be subsumed.

Considered normatively, that description of the distinct explanatory modes typical of the three states had a direct methodological impact, since it logically resulted both into a prescription, which commanded us to consider "all phenomena as subject to invariable natural laws", the "exact discovery of [which] and their reduction to the least number" constituting "the goal of all our efforts" (ibid., p.8), and a proscription, which barred our "positive explanations" from attempting "to explain the real causes of phenomena", since "we regard the search after what are called causes, whether primary of final, as absolutely inaccessible and unintelligible" (ibid.). Hence, by positive standards, good explanations should be driven exclusively by the urge to find the nomological connections that can be observed to exist between different kinds of phenomena. Accordingly, what marked out the positive explanatory approach from its theological and metaphysical counterparts was the emphasis it put on both observation, either with respect to the explanandum (only what was observable was to explained) or the explanans (only what was observable had explanatory power), and generality, a proper explanation consisting in the establishment of a logical relation between a singular observable instance of a phenomenon or fact and a general statement - what Comte misleadingly called a "general fact"-from which it can be inferred ${ }^{2}$. Accordingly, the "fundamental revolution" brought about by the advent of the positive spirit really consisted "in replacing everywhere the inaccessible determination of the causes themselves by the mere search for laws, that is the constant relations that exist between observed phenomena" (Comte, 1995 [1844], p.66). 


\section{THE ASTRONOMICAL MODEL}

As is well known, Comte endorsed a thoroughly naturalistic conception of methodology: as he put it to Valat in I819, "[it] is only by observations appropriately made on the general manner of proceeding in each science, on the various courses followed to arrive at discoveries, on methods in a word, that one can reach sure and useful rules on the way to conduct one's mind" (Comte, I973-1990, t.I, p.59).

In that respect, astronomy, the first natural science in which the positive spirit, after having been awakened by the practice of mathematics, had definitively prevailed, undoubtedly exemplified, in Comte's eyes, something like a methodological ideal3. Accordingly, since it was, "so to speak, the most scientific of all the sciences" (Comte, 1975 [1830-I842], vol.ı, l.19, p.31 I), Comte argued, it was to astronomy that one should turn to "feel, in all its purity, what the positive explanation of a phenomenon is" (ibid., p.zo8).

Such was indeed Comte's own strategy when it came to introducing the readers of the Cours to the basics of a positive explanation, "the most admirable example" of which had been supplied by the "Newtonian law of gravitation" (ibid., l.I, p.26). But what do we mean exactly when we claim that "the general phenomena of the universe are explained" by that law? For Comte, such a law explains phenomena positively because it allows both for their unification and understanding. On the one hand, "this beautiful theory shows us the immense variety of astronomical facts as being only a single fact considered from different points of view" (ibid.). On the other hand, "this general fact is introduced to us as a mere extension of a phenomenon with which we are already eminently familiar and that we consider, for that very reason, as perfectly known, the gravity of bodies at the surface of the earth" (ibid.). As for its logical component, that explanation was exemplary to the extent that the variety of motions characteristic of celestial bodies (whether those of planets around the sun, of satellites around their planets, or of comets), or even phenomena apparently independent

3 Fourier's law of thermal conduction was also invoked by Comte as a prime example of positive explanation (Comte, 1975 [1830-I842], vol.I, I.I, p.26-27), but it had not achieved for physics the kind of unification Newton's law of gravitation brought about in astronomy. 
of any astronomical rationale (such as the tides), were captured by one single, fundamental, empirically observable, nomological relation, from which, consequently, less fundamental generalizations such as Kepler's laws can be derived ${ }^{4}$. From the epistemic standpoint, Newton's law of gravitation properly explained astronomical phenomena, Comte maintained, because it fulfilled the only "logical [i.e. methodological] necessity [...] common to all possible speculations", namely that of "always proceeding from the known to the unknown" (ibid., vol.2, 1.48, p.12I), in that instance by showing that "the continuous tendency of the planets towards the sun and of the satellites towards their planets" could be assimilated to the "common enough phenomena that gravity continually produces at the surface of the globe" (ibid., vol.r, l.24, p.385; see also Comte, I929 [1850-I854], vol.I, chapt.2, p.5 13). And since, in that very case, "we know, with perfect certainty, the existence and the law of both orders of phenomena [i.e. celestial motions and terrestrial gravity]" and "we know, furthermore, that they are identical", we are fully justified in claiming that we have here "their true mutual explanation, by way of an exact comparison of the lesser known phenomena with the better known ones" (Comte, 1975 [1830-1842], vol.ı, l.24, p.388).

What is more, it was on a purely observational basis that both the understanding was gained and the unification achieved: as to the former, because the similarity observed did not rely on "any idle inquiry about the inner nature and primary cause of this celestial action or that terrestrial activity" (ibid.); as to the latter, because it only amounted to "indicating strictly a simple general fact, mathematically ascertained" (ibid.), which both accounted for the already observed phenomena and allowed for a prediction of those to come, thereby opening the way for a continuous process of verification and pragmatic applications (see ibid., l.19, p.308). In other words,

the Newtonian discovery $[\ldots]$ has shown $[. .$.$] how we could, without penetra-$ ting the essence of phenomena, succeed in connecting and assimilating them, so as to reach, with equal precision and certainty, the true final end of our real studies, that exact prevision of events which a priori conceptions are necessarily unable to provide (ibid., l.24, p.392). 
Such an achievement, Comte acknowledged, raised astronomy to "the highest philosophical perfection a science could ever hope for with respect to method, that exact reduction of all phenomena, either regarding their nature or degree, to one single general law" (ibid., l.I9, p.308) and brought to light "the true essential character of all our positive explanations, which consist in [...] connecting and assimilating to the fullest extent possible" (ibid., 1.24, p.388). Now, what remained to be clarified was what exactly this "fullest extent possible" really meant.

\section{AGAINST UNIVERSAL EXPLANATIONS}

Although it offered a model to emulate, the methodological blueprint supplied by Newton's law of gravitation could also result, if misapplied, in faulty attempts at explanation that would drag us back to the theological or metaphysical stages of the development of the human mind. For instance, given the unifying power of Newton's law in the astronomical realm, could it not be reasonably assumed that its actual scope be extended to all natural phenomena, physical, chemical or biological, and perhaps well beyond, to social and moral phenomena? After all, the explanatory drive toward unification, by Comte's own admission, ran through the whole history of human cognitive evolution: "the theological system reached the highest perfection it was capable of when it replaced the varied play of the many independent deities that had been imagined primitively with the providential action of a single being” (ibid., l.I, p.22), just as "the end point of the metaphysical system consists in conceiving, instead of the different particular entities, one single broad general entity, nature, considered as the only source of all phenomena" (ibid.). Likewise, "the perfection of the positive system, toward which it constantly tends, although it is very likely it will never reach it, would amount to being able to represent all the various observable phenomena as so many particular cases of one single general fact, such as gravitation, for example" (ibid.). Yet, Comte nonetheless considered such "attempts at a universal explanation of all phenomena by a single law," even that based on the law of gravitation, which by far looked the most promising, "as eminently chimerical" (ibid., p.40). On the one hand, he argued, "the resources of the human mind are too scarce and the universe 
too complicated for such a scientific perfection to ever be within our reach" (ibid.; see also Comte, 1995 [1844], p.88). On the other hand, there existed, as evidenced by Comte's own encyclopedic scale of the sciences (Comte, 1975 [1830-1842], vol.I, l.2), some sort of irreducible phenomenological pluralism that prevented the reduction of the various kinds of phenomena covered by the different sciences to the laws of one among them 5 . To be sure, no one could deny the objective dependence existing between these various kinds of phenomena (for instance, biological phenomena could not occur in the absence of certain astronomical, physical, and chemical conditions), nor the logical dependence among the different sciences resulting from it (since one had to rely on the methods and results of the previous sciences in the encyclopedic scale to be able to explain less general and more complicated phenomena). But this did not mean that the different categories of phenomena could "all be reduced to one single universal law" (Comte, 1995 [1844], p.87). To believe so, Comte would later claim, was to fall prey to a "materialistic" conception of explanation, fuelled by an excessive confidence in the deductive power of the human mind and which manifested "the spontaneous tendency of lower sciences to dominate, and even absorb, higher ones" (Comte, I929 [I850-I854], vol.3, chapt.I, p.43). Explanatory unification also had its limits.

\section{THE POSITIVE THEORY OF HYPOTHESES}

The exact empirical content of the Newtonian model might also have raised some concern about the positivity of the explanation it was supposed to deliver. For what the "minute analysis of celestial phenomena has proven", Comte claimed, was the accuracy of the "great fundamental law" according to which "all the molecules of our world gravitate around one another, in proportion of their masses and inversely as the squares of their distances" (Comte, 1975 [I830-I842], vol.I, l.24, p.390). Now, the very reference to molecules was problematic since it invoked entities inaccessible to the observational means presently, thereby infringing the empirical requirement characteristic 
of positive explanations. And what about the elusive gravitational force called upon by Newton? What could warrant us in discarding theological or metaphysical explanations that referred to entities that could not be directly observed and nonetheless lead us to regard as a paradigmatic positive explanation a general statement that seemed to fail that very test? Comte had to confront such a predicament, not only because the absence of an appropriate response would seriously weaken the appeal of his own theory of explanation, but also because he was perfectly aware that he had to make empirical good sense of the many entities - such as atoms or forces - whose existence was assumed by the laws of modern, positive science. In other words, on which grounds were we justified to believe in the reality of these hypothetical posits?

With regard to the reference to the gravitational force, it had to be construed, Comte maintained, as a convenient mathematical shorthand for describing the observable quantitative relation connecting various kinds of bodies, nothing more; it in no way ambitioned to "determine what this attraction and this gravity are in themselves, or what their causes are" (ibid., l.I, p.26), since "any attempt in that direction would be, necessarily, utterly illusory as well as perfectly vain" (ibid., l.24, p.388). Furthermore, the "fortunate word of gravitation", invented to state "the fundamental assimilation of gravity with the accelerating force of heavenly bodies" (ibid.), conveniently amended the "vague and unscientific" image of attraction and its description of "the mode of action of the sun on the planets, and of the Earth on massive bodies, by comparison with the effort through which we pull toward us, using a rope, a distant object" (ibid.): according to such a metaphor, "irrespective of the fact that the object be located ten or even a hundred meters away, the same effort will attract it toward us by exactly the same quantity, if one neglects the weight and the rigidity of the rope" (ibid., p.389), whereas gravity correctly depicted "a phenomenon that, for ten times the distance, is necessarily a hundred times weaker" (ibid.). In that very case, the gravitational force invoked by Newtonian theory was fully legitimate since it both connected a vast array of observable phenomena by way of an empirically corroborated mathematical formula and unified their understanding by clearing it from any unfounded analogy. 
On the face of it, the reference to molecules, or what Comte also called the "corpuscular or atomistic theory" (Comte, 1929 [1850-I854], vol.I, chapt.2, p.520) seemed harder to reconcile with the criteria of a positive explanation, especially those set out in the "Theory of hypotheses" elaborated in the $28^{\text {th }}$ Lesson of the Cours. There, whilst acknowledging the limits of both induction (which aims at establishing through observation "the real law of any phenomenon, or the direct analysis of the course of that phenomenon" [Comte, I975 (I830-I842), vol.I, 1.28, p.457]) and deduction (which attempts to specify "its exact and manifest relation with a more general law" [ibid.]), Comte made room for hypotheses that, in the absence of empirical evidence or nomological statements, must be considered as "mere anticipations of what experience and reasoning would have revealed, if the conditions of the problem had been more favorable" (ibid.). For instance, Kepler's painstaking review of the various geometrical figures that might account for the planets' motions around the sun, and his eventual discovery that their orbits followed an elliptical trajectory, was by Comte's own prescriptions, a prime illustration of the positive attitude that must guide "the rational construction and scientific use of hypotheses" (ibid., p.456):

a fact is still not well known, or a law is ignored: a hypothesis about it is formed, fitting as harmoniously as possible with the whole set of data already collected; and science, thus able to develop freely, always ends up leading to new observable consequences, which are likely to confirm or infirm, unequivocally, the original conjecture (ibid., p.458).

Accordingly, as long as the hypothesis only bears on "the laws of phenomena" and can be empirically corroborated, it is perfectly "admissible" (ibid.; see also Comte 1929 [1850-I854], vol.I, chapt.2, p.500). On the contrary, assumptions that focus on the "inner nature", "cause, whether primary or final", or "essential mode of production" of phenomena display "an anti-scientific character and can only [...] hinder the real advancement" (Comte, I975 [1830-1842], vol.I, l.28, p.457) of positive knowledge. 
In light of these methodological prescriptions, what are we to make of the molecular hypothesis embedded in the most general formulation of Newton's law of gravitation? Are we to dispose of it, just like we got rid of the chimerical "fluids" of metaphysical physics, since they were "explicitly imagined as invisible, intangible and imponderable", thereby "necessarily evad[ing] any positive control" (ibid., p.459)? Quite surprisingly Comte argued that such a rejection was not called for: although it is true that "we will necessarily always remain ignorant of the inner structure of real substances", we are nonetheless "rationally authorized to introduce $[\ldots]$ all the hypotheses that will help our thoughts, as long as these artifices are always in accordance with the nature of the corresponding phenomena" (Comte, 1929 [1850-I854], vol.I, chapt.2, p.520).

Therefore, when we study "the general properties of material existence" (ibid.), which is indeed the proper realm of astronomy and physics, we are entitled to ascribe them to the "most minute particles we could conceive of" (ibid.). Since, as already pointed out in the $3^{\text {rd }}$ Lesson of the Cours and in line with the encyclopedic scale of the sciences, "geometry and mechanics constitute [...] the two fundamental natural sciences, in the sense that all natural effects can be considered as mere necessary results either of the laws of extension or of the laws of motion" (Comte, 1975 [1830-1842], vol.ı, l.3, p.74), the ascription of geometric or mechanical properties to molecules, if it leads to a greater unification in our understanding of phenomena and further verifiable empirical predictions, is fully warranted. Yet, Comte also emphasized that this vindication of the "relative legitimacy of the atomistic hypothesis" distinctly delineated "the exact limits of its normal use", without in any way licensing its "absolute extension" (Comte, I929 [I850-I854], vol.I, chapt.2, p.52I). As he put it, "the corpuscular conception, irrevocably reduced to a mere logical artifice, is therefore only appropriate $[\ldots]$ to the first half of inductive cosmology [i.e. astronomy and physics], where its contribution is truly indispensable", but should not be imported into biology, given the truly "synthetic" nature of organic phenomena (which could not be reduced to their material components or divided analytically without loosing their most distinctive features), or even into chemistry, where the properties under scrutiny are already "too complicated and too variable" "to be usefully imputed to inalterable 
atoms" (ibid.) ${ }^{6}$. Just as the scope of the law of gravitation would only encompass a definite set of phenomena, the explanatory purview of the molecular hypothesis was strictly restricted to a certain portion of reality.

\section{EXPLANATION WITHOUT CAUSATION?}

One of the most striking features of Comte's methodological views was undoubtedly his self-professed aspiration to eliminate causation from scientific explanations: "everybody knows", as he put it quite confidently, "that in our positive explanations [...], we do not pretend in any way to disclose [exposer] the generative causes of phenomena [...], but only to analyze accurately the circumstances of their production and to connect them with one another by normal relations of succession and similarity" (Comte, 1975 [1830-I842], vol.I, l.I, p.26).

But what motivated that exclusion of causal reasoning from our explanatory heuristics? One way to account for such a proscription is to note that all the various kinds of "generative causes" targeted by Comte had at least one thing in common: whether "primary" (such as God or the self-generation of the universe) or "final" (such as the realization of the most optimal cosmological order), or pointing towards the "inner constitution" of things responsible for their manifest properties, they all eluded the possibility of being observed empirically. By definition, God could not be scrutinized by standard observational procedures, just as there was a logical impossibility in observing the first moment of the history of the world; the ideal principles supposed to govern the course of events, because of their mental nature, also forwent any sensory appraisal; and "essences" and "substances" definitely exceeded the grasp of our perceptual capacities. Accordingly, since "any proposition that is not strictly reducible to the mere stating of a fact, either particular or general, can in no way allow for any real and intelligible meaning" (Comte, 1995 [1844], p.66), "entities" and "agents" that failed to satisfy such a requirement had to be excluded from our positive explanations.

6 For somewhat different interpretation of Comte's position on atomism and chemistry, see Bensaude-Vincent, 2008. 
Yet, such an eradication of "generative causes" certainly did not amount to the complete disappearance of all causal elements from positive explanatory accounts. As John Stuart Mill, a careful reader of both the Cours and the Système de politique positive, rightfully pointed out, Comte only rejected "questions of ultimate origin, and of Efficient as distinguished from what are called Physical causes", on the grounds that those "are not themselves phenomena" (Mill, I969 [1865], p.292-293). But like "other people he admits the study of causes, in every sense in which one physical fact can be the cause of the other" (ibid., p.293).

A good illustration of the persistence of the causal ingredient was, unsurprisingly, supplied by the Newtonian theory of gravitation, astronomy once again "remaining, with respect to logic, the most perfect type of the general study of nature" (Comte, 1975 [1830-1842], vol.2, 1.58, p.745). Consider for instance the explanation of the tides, where "the elevation of waters" on each point of the globe is said to result primarily from "the passing of the moon at the local meridian" (Comte, 1995 [1844], p.83). In that context, Comte had no qualms resorting to a causal vocabulary when it complied with positive standards: he explicitly acknowledged that the variation of water levels was the "effect" (Comte, I975 [I830-I842], vol.I, l.25, p. 403) of the gravitational pull. Fully "positivized", the causal components of the gravitational theory of the tides gained true explanatory power: taking into account all the relevant observable and quantifiable factors, one could conclude that "only the sun, because of its enormous mass, and the moon, because of its proximity, must produce significant tides", the "action" of the latter "being between two-and-a-half times and three times greater than that of the former" (ibid., p.404). In other words, the moon and the sun were held to be genuine positive causes of terrestrial tides to the extent that their respective "actions" upon Earth, and their variations, are invariably connected to the elevation of waters, and determine, in the sense of being prior to, its degree. And since all the forces referred to belonged to the same kind - that governed by the theory of gravitation-, we were fully entitled to say that we had positively explained tides since we had arrived at an accurate analysis of "the circumstances of their production" and the identification of the "normal relations of succession and similarity [which] connect them 
with one another" (ibid., l.I, p.26), the best proof of the soundness of that "great theory" being afforded by the "exact prevision" of actual tides (ibid., l.25, p.406). So, if causation was defined, in good empiricist manner, as constant conjunction between cause and effect, with the former always preceding the latter, then it surely found its place in Comte's explanatory framework.

\section{EXPLANATION AND ABSTRACTION}

Driven towards unification and observationally warranted, the gravitational theory of the tides undoubtedly represented a truly positive account of these phenomena. But it also shed a precious light on the best manner of obtaining rational and empirically reliable explanations, for one lesson that could be drawn from the way Newton and his followers approached that problem was that of the crucial role abstraction played in the explanatory process.

Comte's philosophical reconstruction of the discovery of the "principle" that the "unequal gravitation of the various parts of the Ocean towards any one of the heavenly bodies of our world, and most particularly towards the sun and the moon" (ibid., p.402) explained terrestrial tides was partly intended to convey this importance of abstraction for explanation. Pursuing the idea that "the action of any heavenly body on the Ocean [...] necessarily tends, in proportion of the unequal energy with which it applies to the various locations, to modify it slightly", Newton could "easily calculate the principal part of the phenomenon" (ibid., p.403), singling out the determining influence of the moon and the sun. Once this general mechanism had been described, other relevant factors could be taken into account, such as, among others, the daily motion of the Earth; and the combined effect of the gravitation resulting from the moon and the sun adequately computed. Finally, in order to arrive at theoretical predictions that matched the tidal data collected beforehand, the nature and configuration of the seabed were reckoned with, which contributed to a better approximation, "in accordance with what had been observed, at each port, [of] the two fundamental coefficients, relative to the average height of the tides and the time of their full accomplishment, thereby rendering all mathematical determinations compatible enough with reality" (ibid., p.406-407). Now, throughout 
this process, abstraction was a key "logical procedure" (Comte, I929 [1850-I854], vol.I, chapt.2, p.5oI) in that it allowed for the putting aside of the "secondary irregularities that would prevent one from grasping the main law with which one then tries to connect every minor circumstance of the phenomenon at hand" (ibid.). Such was, Comte claimed, "the only rational course that may lead [...] to the real discovery of the fundamental laws of nature" and that was indeed the general method actually followed, not only for the tides, but for rational mechanics at large, considering "first celestial motions through their most essential features, carefully ignoring [faisant abstraction] all the perturbations, which could then be gradually related to that same principle of gravitation resulting from that mere initial appraisal" (Comte, I985 [1844], p.474; see also Comte, 1929 [1850-I854], vol.I, chapt.2, p.502). If one had proceeded the other way around, Comte concluded, "considering all these phenomena only in their full actual complexity, it is clear that no mechanical theory would ever have been established" (Comte, 1985 [1844], p.474). In other words, a good positive explanation was not merely an explanation based on laws from which phenomena could be derived or predicted, but also an explanation that could be capable of singling out essential conditions from accessory circumstances or, to put it in causal language, to weigh the various causes according to their importance in the production of the phenomena, clearly distinguishing between primary "influences" and secondary "perturbations"7.

Astronomy certainly made it easier to grasp the role of abstraction and the importance of fundamental laws in positive explanations, primarily because of the simplicity of the phenomena considered, of the analytical approach prevailing in their study, and of the fortunate, although contingent, fact that they could be reduced to a few basic laws, most notably that of gravitation. But the search for the most fundamental laws, or for the most important causes, was nonetheless ubiquitous among the sciences of the encyclopedic scale. So, irrespective of their

7 In his later years, Comte would claim that this explanatory scheme, primarily borrowed from mechanics, was merely a special case of Broussais' principle (according to which the pathological state of a phenomenon is merely a quantitative variation of its normal state), which he then generalized to all "encyclopedic ranks"; see Comte, 1929 [1850-1854], vol.2, chapt. 7, p.440-444. 
subject, a definite explanatory scheme was shared by all sciences and, accordingly, it was only through its study "that sociologists" could get "an appropriate general idea of the essential attributes of scientific positivity", and especially of "what the real explanation of any phenomenon consists in" (Comte, I975 [1830-I842], vol.2, 1.49, p.167). Of course, it would remain for sociologists to discover how to apply properly that methodological lesson to the study of social phenomena.

\section{SOCIOLOGICAL EXPLANATIONS}

For Comte, no serious doubt could entertained as to the methodological orientation that would prove the most appropriate for the scientific study of social phenomena, the last domain of reality not to have been fully positivized: anyone duly acquainted with the doctrines and methods of both the inorganic and organic sciences should clearly see that "our positive explanations constantly amount [...] to connecting various phenomena with one another, either as similar or successive, without us being in any way capable of, in any respect, really observing anything beyond the invariable fact of such similarity or succession" (ibid., 1.58, p.724).

Thanks to the knowledge of these "filiations" and "successions", Comte claimed, we would be able "to reach the true aim of any sound contemplation of nature", namely to have phenomena "on the one hand, clarified [éclaircis] and, on the other hand, predicted, by one another" (ibid.). The blueprint was straightforward, but how did it exactly play out in the sociological sphere?

Quite simply actually, since the architectonics of positive sociology drew on a doctrinal distinction, which originated in mechanics but was only fully elaborated in biology, between statics and dynamics, social statics studying "the conditions of existence of society" whilst social dynamics dealt with "the laws of its continuous motion" (ibid., l.48, p.rog). Accordingly, it considered "each phenomena under the dual elementary perspective of its harmony with co-existing phenomena and its concatenation [enchainement] with the previous state and the following state of human development" (ibid., p.136), striving to discover "the true general relations connecting all social facts" (ibid.). Hence, within a positive perspective, "any of them [...] is held to be explained, in the truly scientific 
meaning of the term, when one has succeeded in properly connecting it either to the whole corresponding situation or to the whole previous motion" (ibid.).

Now, this generic characterization somewhat downplayed the variety of explanatory arguments the positive sociologist could rely on. As for social, statics, there were indeed various ways one could positively explain a given social phenomena, a diversity that, in the end, traced back to a distinctive feature of the social world, namely the solidarity existing among the various elements that composed social aggregates such as civilizations or societies. Given the preponderance of that "social consensus", which Comte considered the "key idea of social statics" (ibid., p.r I8), one was perfectly entitled to resort to structural explanations: the existence or action of a specific social element would be corroborated by the acknowledgement that it is an indispensable part of the "social organism" (ibid., p.I I2) at large; for instance, according to Comte, government will always be divided between a temporal and a spiritual power, since it has been observed that such a division has been an essential element of any society observed so far. But one can also use functional explanations, extending to social phenomena the "principle of the conditions of existence" (ibid., vol.I, 1.40, p.738) already prevalent in biology: since "there is no organ without function and no function without organ" (ibid.), once the existence of a social group is duly attested, it might be inferred that it exists to serve a certain purpose, just as one might infer from the existence of a given social need the necessity of a group or mechanism to fulfill it. For instance, just as the sacerdotal class catered for the spiritual needs of populations in theological societies, scientists, in the positive state, will have to provide modern societies with a new rational creed. Furthermore, there is always the possibility of supplying mechanical explanations, which would shed light on the "mutual actions and reactions that the various parts of the social system constantly exert on one another" (ibid., vol.2, 1.48, p.I I ), just as when one explains the progressive disappearance of the military spirit by the rise of industrial collaboration. Finally, all these different kinds of static explanations fully satisfied "the most unquestionable criteria of scientific positivity", namely "the principle of rational prevision", since they all allowed for "sociological previsions, based on an 
exact knowledge of these necessary relations, [which] will be duly aimed at deriving from one another, in accordance with future direct observations, the various static indications relative to each mode of social existence" (ibid.).

As to social dynamics, its explanations primarily consisted in showing each social state, historically considered, "as the necessary result of the previous one and the indispensable force behind the next” (ibid., p.r23). Here, Comte's intellectualism, that is the primacy he granted to the development of the mind in human evolution, played a key explanatory role, since any given transformation, whether technological, political, esthetic, religious or moral, would have to be connected with a corresponding intellectual advancement. That was why the law of the three states was so crucial in Comte's overall scheme: it identified the main causal influence at work in the history of mankind, from which all other social trends could be, more or less directly, derived. And since that law was, so to speak, maximally explanatory - it unified the whole field cognitive phenomena under a single law; it clarified the fact of mental progress, because, as Comte put it (ibid., vol.ı, l.ı, p.22), the intellectual development of mankind as a whole was mirrored in our personal intellectual development; and, as illustrated by the Cours itself, it was corroborated by the history of the sciences-any explanatory inference properly drawn from it would partake in its positivity.

To be sure, the global perspective favored by social dynamics seemed to ignore an awful lot of historical details, thereby apparently belying the selfprofessed dedication of the positive method to the study of facts; but as in static explanations, the synthetic spirit also prevailed in dynamic ones; hence Comte's decision to resort to the legitimate "hypothesis of a single people", borrowed from Condorcet, around which he structured the narrative of the Cours, so as to be able to present a unified and rational picture of "all the successive social modifications actually observed in distinct populations" (ibid., vol.2, 1.48, p.i23), which would have been deprived of any fix meaning had they not been connected first, be it by a mere provisional hypothesis, to the fundamental laws of social development" (ibid., p.I40). 
Similarly, given the importance ascribed to predictive accuracy as a reliable sign of explanatory validity, one might have been puzzled by Comte's reluctance in the Cours, and later in the Système, to deliver clear indications of the future course of events that could be precise enough to infirm or confirm sociological theories. Yet, one might still have argued, relying on Comte's own analysis, that, due to the complexity of social phenomena, which were indeed the most intricate of all natural phenomena, the best one could hope for was merely the formulation of large scale historical trends. Accordingly, one would have to confine oneself to conjecturing something like "the continuous increase of any disposition, whether physical, intellectual, moral or political, combined with the indefinite decrease of the opposite disposition, from which will result the scientific prediction of the ultimate prevalence of the one and the final demise of the other" (ibid., p.I5 I).

More concretely, Comte maintained, "the general result of our fundamental evolution" would amount to, besides "improving the material condition of man, through the continuous extension of its action on the external world",

developing primarily, through an increasingly significant exercise, our most eminent faculties, either by constantly reducing the empire of physical inclinations, and by stimulating further our social instincts, or by constantly exciting the development of intellectual functions, even the highest, and by increasing spontaneously the regular influence of reason on the conduct of man (ibid., 1.51, p.204).

But to look for a more specific kind of prediction would have been sheer prophecy or a vain search for absolute certainty. Such was, Comte concluded, "the only kind of precision, compatible with the excessive complexity of these phenomena, upon which constantly act so many influences, some of them regular, some others accidental” (ibid., l.48, p.I5 I). But then, and even if it accepted to settle for such a moderate predictive ambition, sociology still had to make sure it had correctly addressed that challenge of causal complexity, lest its conjectures be deprived of any empirical value. 


\section{PRINCIPAL AND SUBORDINATE CAUSES IN SOCIOLOGY}

It was no coincidence that the discovery of the law of the three states prompted Comte to find a way of disentangling the causal web characteristic of social phenomena. For, as he put it in his Plan des travaux scientifiques nécessaires pour réorganiser la société, although the "experience of the past proves most decisively that the progressive development of civilization is subject to a natural and irrevocable course" (Comte, 1998 [1822], p.93), it also showed that "the course of civilization is [...] modifiable, to greater or lesser extent, in its speed, within certain limits, by several physical and moral causes" (ibid., p.97). Given the ultimate political purpose of his philosophical enterprise-providing a comprehensive scheme for the government of modern societies based on a scientific understanding of their historical evolution-Comte could not eschew the exact determination of the various circumstances that might hasten or hinder the development he was supposed to assist ${ }^{8}$. And to do so, Comte indeed proposed the very same approach used by Newtonian mechanics": one must first try "to establish the general course of the human race, in abstraction from all the various causes which can modify the rate at which civilization develops", and only then "assess the influence of these modifying causes" (ibid., p.r39). Hence the "obligation to treat the first order of works before the second" (ibid.) to arrive at a proper sociological explanation.

The dire consequences of infringing that rule were perfectly illustrated, in Comte's eyes, by the unfortunate case of Montesquieu. A key contributor to the "positivization" of social science, for he was the first to see clearly that the "general idea of law" could also be applied to political facts, Montesquieu nonetheless seriously erred when, trying "to determine the political influence of local physical circumstances" (ibid., p.II4), "he much exaggerated the influence of climates" (ibid.), erroneously regarding the latter as the primary cause of many political differences among nations. That error was "inevitable", Comte claimed, because Montesquieu considered "the indirect and subordinate cause", i.e. climate, "before the direct and principal cause" (ibid.), that

8 On the relation between positive sociology and positive politics, see Karsenti, 2006.

9 See Section 6 supra. 
is the development of mankind. "No doubt climate does exercise a very real influence on political phenomena", Comte acknowledged, but it was "limited to accelerating or retarding, up to a point, the natural course of civilization, which cannot be diverted by these modifications" (ibid.). Yet, Montesquieu's mistake still shed a precious light on the right way of explaining the influence "of all the other causes which can modify the course of civilization in its speed without altering its essence" (ibid.). For this influence, Comte argued, "will only be capable of being determined with precision when the natural laws of civilization have been established, by first abstracting from all these modifications", just as astronomers did when they "began studying the laws of planetary movements, abstracting from perturbations" (ibid.). Had they tried to take into account the irregularities from the beginning, Comte concluded, "no exact theory could ever have been formed" (ibid., p.i15).

Comte zealously applied that prescription in Lessons 46 to 57 of the Cours, where he exposed the most basic laws of social phenomena, whilst reminding his readers, as some sort of cautionary tale, of Montesquieu's blunder and his confusion of the "fundamental action" of human development with the "mere modification" brought about by climate, of his mistaking "essential laws" for "perturbations" (Comte, I975 [1830-1842], vol.2, 1.47, p.87). But despite the terminological sanitization, the key issue still remained that of distinguishing the "fundamental cause" from the "perturbing" ones (ibid., l.48, p.I32) in sociological analysis. At present, Comte acknowledged, with sociology still trying to establish its nomological basis, it would have been "premature" to draw "a definitive classification of the various modifying influences" (ibid., p.r33); but he nonetheless singled out as the most important "sources of social variations", "race", "climate" and "political action" (ibid.). Yet, Comte also made clear that one should be extremely cautious when attempting to explain social phenomena, either static or dynamic, by invoking these influences. As to the latter, men generally tended to exaggerate their power over the course of human affairs, when they in fact could merely hinder or hasten its speed. As for climate and race, the mere comparison of various populations to assess their impact was misleading, for it neglected to take into account the nature and direction 
of human evolution: too often, Comte lamented, one ascribed to the "action [of climate] social differences that might primarily be traced to the inequality of evolution" (ibid., p.r.47), just as one could easily "confuse the influence of race and that of the social era, either by exaggerating or downplaying one or the other" (ibid., p.i48). Beyond these methodological warnings, what Comte seemed ready to assert about these "modifying influences" remained quite generic, although it clearly marked the ultimate primacy and universality of social causes: on the one hand, "local physical causes", such as climate, although "very powerful at the beginning of civilization", "gradually lose their empire as the naturel course of human development allows more and more for the neutralization of their action"; on the other hand, "one should not overstate "the necessary influence of organic diversities on mental conceptions", since "the knowledge characteristic of all the various races do nonetheless have a genuinely common basis, which is more or less correctly understood by more or less perfect, but still radically homogeneous, understandings" (ibid., 1.58, p.729).

Ten years or so later, the Système de politique positive eventually supplied what Comte regarded as the definitive, if sketchy, scientific assessment of the influence of climate and race on social phenomena. Recast within the context of a compulsively finicky "positive theory of social modificability" (Comte, 1929 [1850-1854], vol.2, chapt.7, p.430), Comte's appraisal of these two classes of "modifications characteristic of social existence" (ibid., p.439) was firmly grounded in the familiar principle that they would "bear only on the intensity of phenomena in static sociology, and on their speed in dynamic sociology" (ibid., p.444), without transforming their fundamental laws. To this, Comte added the noteworthy qualification that social evolution itself progressively mitigated their effects. For instance, due to technological improvements, Earth "tends to become uniformly habitable, except for too adverse locations", a proof that "civilization almost cancels influences" such as climate and a momentous inversion in the history of mankind Comte oddly chose to illustrate by pointing out that "the artificial heat of Russian cities often renders menstruation there as precocious as it is in India" (ibid., p.46I). As for racial diversity, which he ascribed to "local influences slowly accumulated by heredity, until it produced the 
corresponding maximum of organic variation" (ibid., p.449), Comte noted that it also could only "affect the speed of our common evolution, without altering in any way its nature or its course". But its impact also declined both because "an increasing mixing [of races] tends to destroy directly this source of modifications" and because "the whole of human development gradually exempts us from it" (ibid., p.46I). So, it was only once one had grasped correctly the scheme according to which human evolution unfolded-something Comte dogmatically asserted he had done in the Système - that the weight of these "modifiers" (ibid., p.45I) on social phenomena could be duly assessed. Otherwise, "mere differences in intensity and speed end up being paraded as radical diversities, thereby casting aside any authentically general conception, and with it any sound explanation” (ibid., p.450). In other words, good explanatory sociological practice relied on the positive principle that "progress [was] the necessary development of order" (ibid., p.425), a clear understanding of its evolutionary laws, and the acknowledgment that the power of "modifying influences" such as climate and race was historically relative and gradually decreasing. Such was the proper way of disentangling the causal web social phenomena were caught in.

\section{CONCLUSION Explanation as development}

Although it might come as a surprise, since Comte is not exactly a fashionable philosophical reference these days, there is much in his views on scientific explanation that a reader interested in the recent literature on the subject will find familiar and relevant to his concerns: the idea that a good explanation must promote the unification and understanding of phenomena, whilst allowing for empirical verifications; the emphasis put on laws as a key element of the explanatory process; the inquiry into the proper scope of explanations and the role hypotheses play in it; the appraisal of the causal component of explanation and the search for the best way of weighing causes. Of course, there is also much in the manner Comte addressed these questions and the answers he suggested one could disagree with, object to, or simply question: his endorsement of a single explanatory model for all kinds of phenomena; his belief that the law of 
the three states was the explanatory key of sociological investigations; the intellectualism and historicism on which it depended; or his downplaying of nonsocial causes (such as climate and race) in the explanation of social phenomena. For want of space, I will not attempt to settle the score here. Rather, I would like to consider one final aspect of Comte's views on explanation that, although not as apparent as what we have covered so far, is nonetheless crucial for a complete understanding of his conception of the matter.

In De l'explication dans les sciences, Émile Meyerson 1927 (192I) took issue at the philosophical theory that reduced explanation to a mere process of subsumption under phenomenal laws, a position for which, he claimed, Comte's positive philosophy provided an almost perfect illustration. According to that view, "when we have properly scrutinized, penetrated a phenomenon, when we have rendered obvious its most tenuous details [...], we will have explained it, i.e. our understanding of that very phenomenon will be perfect and our intelligence will therefore have to declare itself fully satisfied” (ibid., p.I8). As we have seen (section 2 supra), Comte's emphasis on understanding as intelligibility certainly echoed that dimension of explanation. But there was more to it than met the eyes, literally.

For, traced to its Latin root explicare, this cognitive operation evoked the process of "unfolding" a piece of fabric, so as to show "what it hid beneath its folds" (ibid., p.I7). Now, this metaphor of "unfolding" was at the heart of Comte's view of social evolution, seen as the "simple spontaneous development, gradually aided by an appropriate cultivation, of the preexisting fundamental faculties that constitute our nature" (Comte, I975 [1830-1842], vol.2, l.48, p.i29), a view that ran through the Plan ${ }^{10}$ and the Cours ${ }^{11}$, before becoming a central tenet of the Système ${ }^{12}$. So, when he wanted to provide a "summary explanation" (ibid., 1.51, p.202) of the progressive course of human affairs, it was naturally through the lens of the developmental perspective that he did so: as he put it, "the most eminent civilization $[. .$.$] really consists only$

10 See Comte, 1998 (I822), p.90, p.93, p.95, p.97, p.105, p.107-108 and p.II3.

II See Comte, 1975 [1830-1842], vol.2, I.48, p.127-129.

12 See supra, p.28. 
in a more pronounced manifestation of the main properties of our species, which, at first concealed by an inevitable numbness, could only become salient enough in a high degree of social life" (ibid.). History was the medium in which this development took place and it was the goal of sociology to explain it by stating the laws of its unfolding. Such was the last, but certainly not the least, acceptation of the term "explanation" as Comte understood it.

\section{BIBLIOGRAPHY}

BENSAUDE-VINCENT B., 2008, "Une science sous influence positiviste?" in Id.,

Matière à penser: Essais d'histoire et de philosophie de la chimie, Nanterre,

Presses universitaires de Paris Ouest, p.199-249.

COMTE A., 1929 (1850-1854), Système de politique positive, 4 vol., Paris, Au siège de la Société positiviste.

-, 1973-1990, Correspondance générale et confessions, 8 t., Paris, Éditions de l'EHESS \& Vrin.

-, 1975 (1830-1842), Cours de philosophie positive, 2 vol., Paris, Hermann.

-, 1985 (1844), Traité philosophique d'astronomie populaire, Paris, Fayard.

-, 1995 (1844), Discours sur l'esprit positif, Paris, Vrin.

-, 1998 (I822), Plan of Scientific Work Necessary for the Reorganization of Society, in Id., Early Political Writings, Cambridge, Cambridge University Press.

FEDI L., 2000, Auguste Comte, Paris, Les Belles Lettres.

KARSENTI B., 2006, Politique de l'esprit. Auguste Comte et la naissance de la science sociale, Paris, Hermann.

MEYERSON É., 1927 (1921), De l'explication dans les sciences, Paris, Payot.

MILL J.S., 1969 (1865), Auguste Comte and Positivism, in Id., Essays on Ethics, Religion and Society, Toronto \& London, University of Toronto Press \& Routledge and Kegan Paul. 
